\title{
TBX5 loss-of-function mutation contributes to atrial fibrillation and atypical Holt-Oram syndrome
}

\author{
DONG-FENG GUO ${ }^{1}$, RUO-GU LI ${ }^{2}$, FANG YUAN ${ }^{2}$, HONG-YU SHI ${ }^{2}$, XU-MIN HOU ${ }^{2}$, XIN-KAI QU ${ }^{2}$, \\ YING-JIA XU ${ }^{2}$, MIN ZHANG $^{2}, \mathrm{XU} \mathrm{LIU}^{2}$, JIN-QI JIANG ${ }^{3}$, YI-QING YANG ${ }^{2,4,5}$ and XING-BIAO QIU ${ }^{2}$ \\ ${ }^{1}$ Department of Emergency Medicine, Shanghai Gongli Hospital, Second Military Medical University, Shanghai 200135; \\ Departments of ${ }^{2}$ Cardiology, ${ }^{3}$ Emergency Medicine, ${ }^{4}$ Cardiovascular Research Laboratory and ${ }^{5}$ Central Laboratory, \\ Shanghai Chest Hospital, Shanghai Jiao Tong University, Shanghai 200030, P.R. China
}

Received May 9, 2015; Accepted March 14, 2016

DOI: $10.3892 / \mathrm{mmr} .2016 .5043$

\begin{abstract}
Previous genome-wide association studies have demonstrated that single nucleotide polymorphisms in T-box $(T B X) 5$ are associated with increased susceptibility to atrial fibrillation (AF), and a recent study has causally linked a TBX5 mutation to atypical Holt-Oram syndrome and paroxysmal AF. However, the prevalence and spectrum of TBX5 mutations in patients with AF remain to be elucidated. In the present study, a cohort of 190 unrelated patients with idiopathic AF were prospectively recruited, with 400 unrelated healthy individuals recruited as controls. The coding exons and flanking introns of the TBX5 gene were sequenced in the participants. The functional characteristics of the mutant TBX5 were delineated in contrast with its wild-type counterpart using a dual-luciferase reporter assay system. As a result, a novel heterozygous TBX5 mutation, p.P132S, was identified in an index patient with AF, with a mutational prevalence of $\sim 0.53 \%$. Genetic analysis of the proband's family showed that the mutation co-segregated with AF, and was transmitted in an autosomal dominant pattern. The missense mutation was absent in the 800 control chromosomes, and the altered amino acid was completely evolutionarily conserved across species. Functional analyses revealed that the mutant TBX5 had significantly reduced transcriptional activity. Furthermore, the mutation markedly decreased the synergistic activation between TBX5 and NK2 homeobox 5, another transcription factor which has been causatively linked to AF. The present
\end{abstract}

Correspondence to: Dr Xing-Biao Qiu, Department of Cardiology, Shanghai Chest Hospital, Shanghai Jiao Tong University, 241 West Huaihai Road, Shanghai 200030, P.R. China

E-mail: qxingbiao@sina.cn

Dr Yi-Qing Yang, Department of Cardiovascular Research Laboratory, Shanghai Chest Hospital, Shanghai Jiao Tong University, 241 West Huaihai Road, Shanghai 200030, P.R. China

E-mail: dryyq@tongji.edu.cn

Key words: atrial fibrillation, genetics, transcription factor, T-box 5, reporter gene assay study was the first, to the best of our knowledge, to report on the association between a TBX5 loss-of-function mutation and increased susceptibility to AF. These results provide novel insight into the molecular mechanism underpinning $\mathrm{AF}$, and have potential implications in the development of novel prophylactic and therapeutic strategies for AF, the most common form of sustained cardiac arrhythmia.

\section{Introduction}

Atrial fibrillation (AF), a supraventricular tachyarrhythmia with chaotic atrial electrical activation and consequent ineffective atrial contraction, is the most common form of sustained cardiac arrhythmia, accounting for approximately one-third of hospitalizations for various types of cardiac rhythm disturbances (1). The estimated prevalence of AF is $1-2 \%$ in the worldwide population, and the incidence increases rapidly with advancing age, rising from $6 \%$ in individuals aged $>65$ years to $10 \%$ in individuals aged $\geq 80$ years (1-3). $\mathrm{AF}$ can result in a reduction in quality of life, poor exercise tolerance, thromboembolic stroke, congestive heart failure and increased rates of mortality (1). AF confers a 5-fold increase for the risk of stroke, and a 2-fold increase for the risk of heart failure and succumbing to ortality (1). Therefore, AF represents a substantial socioeconomic burden, which is likely to increase in the future due to the ageing population $(4,5)$. Despite significant morbidity and mortality rates, the etiologies responsible for AF in a considerable proportion of patients remain to be elucidated.

$\mathrm{AF}$ is frequently associated with various cardiac disorders and noncardiac comorbidities (1), including valvular heart disease, hypertensive heart disease, ischemic heart disease, renal failure, thyroid dysfunction, diabetes and inflammation $(6,7)$. However, in $15-30 \%$ of patients, AF occurs in the absence of previously associated pathology or predisposing factors, defined as idiopathic AF, of which up to $15 \%$ exhibits familial clustering and is termed familial AF (8). In previous years, an increasing number of population-based studies have demonstrated that genetic defects are pivotal in the pathogenesis of $\mathrm{AF}$, and mutations in $>25$ genes, including those coding for ion channels, transcription factors and signaling molecules, have been causally linked to AF $(8,9-23)$. However, AF is a 
genetically heterogeneous disorder, and the genetic determinants underpinning AF in a significant number of cases remain to be elucidated.

A previous study by Sinner et al (24) identified five novel AF susceptibility loci by using a combination of genotyping, expression quantitative trait loci mapping and functional analysis, including a locus on chromosome $12 \mathrm{q} 24$ intronic to TBX5. The AF-associated single nucleotide polymorphism (SNP) at the TBX5 locus, rs10507248, which was also significantly associated with ischemic stroke, was shown to modulate the expression of $T B X 5$ in human atrial tissues. In a genome-wide association investigation, Holm et al (25) found that the SNP in TBX5 was positively associated with the electrocardiograph PR interval, QRS duration, QT interval, and with common arrhythmias, including AF and advanced atrioventricular block. In addition, the associations between the SNP in TBX5 and the electrocardiographic parameters (PR interval, QRS duration and QT interval) and AF were replicated independently in a Chinese Han population (26). As TBX5 is widely expressed in the heart, including the atria, atrioventricular node and ventricular bundle branches, and mutations in $T B X 5$ have been reported to underlie Holt-Oram syndrome, features of which include forelimb malformations and congenital heart defects, atrioventricular conduction abnormalities and AF, of which AF is the predominant phenotype $(27,28)$, the present study hypothesized that genetically defective TBX5 may predispose to AF in a subset of patients. Therefore, the present study aimed to identify novel mutations in TBX5 responsible for AF, which may have potential implications for genetic counseling of AF patients.

\section{Materials and methods}

Study subjects. In the present study, subjects were recruited from the Chinese Han population at the Shanghai Gongli Hospital and Shanghai Chest Hospital (Shanghai, China), and included 190 unrelated patients with idiopathic AF (98 males; 92 females; age range, 38-57 years) and 400 unrelated healthy individuals (206 males; 194 females; age range, 38-59 years), which were used as controls. Whenever available, the index patient's first- and second-degree relatives were also enrolled. All participants underwent detailed clinical evaluation, including family history, medical history, physical examination, routine biological tests, a standard 12-lead electrocardiogram and a transthoracic echocardiogram. Subjects with structural heart disease, ischemic heart diseases, hypertension, diabetes, or any other known risk factor for AF were excluded from the investigation. The patients were clinically classified in accordance with the 2014 AHA/ACC/HRS Atrial Fibrillation Guideline (1). The classification was as follows: Idiopathic AF, AF occurring in individuals without other cardiac or systemic diseases; familial AF, idiopathic AF occurring in two or more first-degree relatives; paroxysmal AF, AF that terminates spontaneously or with intervention within 7 days of onset; persistent $\mathrm{AF}, \mathrm{AF}$ with a duration of $>7$ days; longstanding persistent $\mathrm{AF}$, continuous AF for a duration of $>12$ months; permanent AF, when a joint decision was made by the patient and clinician to cease further attempts to restore and/or maintain sinus rhythm. The present study conformed to the principles of the Declaration of Helsinki (29). The experimental protocol was reviewed and approved by the ethics committee of Shanghai Chest Hospital, Shanghai Jiao Tong University (Shanghai, China). Prior to the investigation, all the participants provided written informed consent.

Genetic screening for TBX5 mutations. Peripheral venous blood samples and clinical data were collected from all participating subjects (Table I). Genomic DNA was isolated from blood leukocytes using a Wizard Genomic DNA Purification kit (Promega, Madison, WI, USA). The primers used for amplification of the coding exons and splice junctions of TBX5 by polymerase chain reaction (PCR) were designed, as described previously (30), and manufactured by Sangon Biotech Co., Ltd. (Shanghai, China). The primer sequences were as follows: Exon 1 (428 bp) forward (F), 5'-GACGCC ATAATCCTCTGGGC-3' and reverse (R), 5'-AAGAGCTGC CTCCACCTACT-3'; exon 2 (598 bp) F, 5'-GTCATGATC TCCGCCGTGTC-3' and R, 5'-GAACAGCGAAGGAGG CAGCG-3'; exon 3 (493 bp) F, 5'-AGGGCGAGGCCGAGT TTATG-3' and R, 5'-ACGACCCTTGGAGTTGGGTC-3'; exon 4 (462 bp) F, 5'-GGCACTTTTAGGGTTCGCCC-3' and R, 5'-TCTCCTCATCGGCACACCAG-3'; exon 5 (480 bp) F, 5'-GAGTCCAGGCCAGTGAGGTC-3' and R, 5'-CCGCTT TTCCAGAGGCGTTG-3'; exons 6 and 7 (675 bp) F, 5'-TGG TGCGCTTCTCCTAACACT-3' and R, 5'-CTCCGACGCCCC ATGCGAGG-3'; exon 8a (487 bp) F, 5'-CCCTGATCCGAC GTCTTTCC-3' and R, 5'-AACACGACAACTCCATGTGC-3'; exon 8b (437 bp) F, 5'-CTGAGTGGGTGCACACTGGA-3' and R, 5'-AGGGCTGGAGGATTCGCTTC-3'; and exon 8c (676 bp) F, 5'-ACTTGGGGTCTCGGGCACGC-3' and R, 5'-CGAACTTCGGGGCTGTGCAG-3'.

Amplification of the genomic DNA fragment by PCR was performed on a Veriti Thermal Cycler (Applied Biosystems; Thermo Fisher Scientific, Inc., Waltham, MA, USA) using a $25 \mu \mathrm{l}$ reaction mixture consisting of $2 \mu \mathrm{l}$ genomic DNA (100 ng/ $\mu \mathrm{l}$ ), $2.5 \mu \mathrm{l}$ 10X Taq Buffer (Qiagen, Hilden, Germany), $5 \mu 1$ 5X Q Solution (Qiagen), $2 \mu \mathrm{l}$ dNTP Mixture (2.5 mM each; Takara Biotechnology Co., Ltd., Dalian, China), $0.5 \mu \mathrm{l}$ of each primer (20 mM each), $0.25 \mu 1$ HotStar TaqDNA polymerase (5 U/ $\mu \mathrm{l}$; Qiagen) and $12.25 \mu \mathrm{l}$ deionized $\mathrm{H}_{2} \mathrm{O}$. The thermal cycling conditions were as follows: An initial pre-denaturation at $95^{\circ} \mathrm{C}$ for $15 \mathrm{~min}$, followed by 35 cycles of denaturation at $95^{\circ} \mathrm{C}$ for $1 \mathrm{~min}$, annealing at $62^{\circ} \mathrm{C}$ for $30 \mathrm{sec}$ and extension at $72^{\circ} \mathrm{C}$ for $1 \mathrm{~min}$, with a final extension at $72^{\circ} \mathrm{C}$ for $5 \mathrm{~min}$. Each amplicon was sequenced using a BigDye ${ }^{\circledR}$ Terminator v3.1 Cycle Sequencing kit (Applied Biosystems; Thermo Fisher Scientific, Inc.) under an ABI PRISM 3130 XL DNA analyzer (Applied Biosystems; Thermo Fisher Scientific, Inc.). The identified variant was validated by the resequencing of a second PCR product, and queried in the SNP (http://www.ncbi. nlm.nih.gov/SNP), 1000 Genomes (www.1000genomes.org), and Exome Variant Server (EVS; http://evs.gs.washington. edu/EVS) databases to confirm it as novel.

Alignment of multiple TBX5 protein sequences across species. The amino acid sequences of multiple TBX5 proteins from various species, including human (NP_000183.2), chimpanzee (XP_001154140.2), monkey (XP_001111737.1), dog (XP_005636327.1), cattle (NP_001179678.1), mouse (NP_035667.1), rat (NP_001009964.1), fowl (NP_989504.1), 
Table I. Baseline characteristics of the patients with idiopathic AF and control individuals.

\begin{tabular}{|c|c|c|c|}
\hline Variable & Patients $(n=190)$ & Controls $(n=400)$ & P-value \\
\hline \multicolumn{4}{|l|}{ Demographics } \\
\hline Age (years) & $53 \pm 9$ & $54 \pm 8$ & 0.1738 \\
\hline Male, n (\%) & $98(52)$ & $206(52)$ & 0.9857 \\
\hline BMI $\left(\mathrm{kg} / \mathrm{m}^{2}\right)$ & $24 \pm 4$ & $24 \pm 3$ & 1.0000 \\
\hline Positive family history of AF (\%) & $82(43)$ & $0(0)$ & $<0.0001$ \\
\hline \multicolumn{4}{|l|}{ Type of AF } \\
\hline Paroxysmal AF (\%) & $72(38)$ & $0(0)$ & $<0.0001$ \\
\hline Persistent AF (\%) & $55(29)$ & $0(0)$ & $<0.0001$ \\
\hline Long-standing persistent AF (\%) & $37(19)$ & $0(0)$ & $<0.0001$ \\
\hline Permanent AF (\%) & $26(14)$ & $0(0)$ & $<0.0001$ \\
\hline \multicolumn{4}{|l|}{ Echocardiographic parameters } \\
\hline LAD (mm) & $38 \pm 6$ & $35 \pm 5$ & $<0.0001$ \\
\hline $\operatorname{LVEF}(\%)$ & $63 \pm 5$ & $63 \pm 6$ & 1.0000 \\
\hline \multicolumn{4}{|l|}{ Medical history } \\
\hline Stroke or TIA $(\%)$ & $10(5)$ & $0(0)$ & $<0.0001$ \\
\hline $\operatorname{ICD}(\%)$ & $5(3)$ & $0(0)$ & 0.0033 \\
\hline \multicolumn{4}{|l|}{ Treatment of AF } \\
\hline Catheter based ablation (\%) & $86(45)$ & $0(0)$ & $<0.0001$ \\
\hline Pharmacological cardioversion $(\%)$ & $51(27)$ & $0(0)$ & $<0.0001$ \\
\hline Electrical cardioversion $(\%)$ & $28(15)$ & $0(0)$ & $<0.0001$ \\
\hline Follow-up $(\%)$ & $25(13)$ & $0(0)$ & $<0.0001$ \\
\hline
\end{tabular}

$\mathrm{AF}$, atrial fibrillation; $\mathrm{BMI}$, body mass index; $\mathrm{LAD}$, left atrial diameter; LVEF, left ventricular ejection fraction; TIA, transient ischemic attack; ICD, implanted cardiac defibrillator.

zebrafish (NP_570990.1) and frog (NP_001185697.1), were aligned using the online Multiple Sequence Comparison by Log-Expectation program (http://www.ebi. ac.uk/Tools/msa/muscle/).

Expression plasmids and site-directed mutagenesis. The TBX5-pcDNA3.1 expression plasmid was constructed, as described previously (30). Briefly, the full-length wild-type cDNA of the human TBX5 gene were amplified by PCR using the cDNA prepared in our previous study (9), digested with EcoRI (Takara Biotechnology Co., Ltd.) and NotI (Takara Biotechnology Co., Ltd.), and subsequently inserted into the pcDNA3.1 vector (Invitrogen; Thermo Fisher Scientific, Inc.). The mutant TBX5-pcDNA3.1 was generated by PCR-mediated site-directed mutagenesis using a QuickChange II XL Site-Directed Mutagenesis kit (Stratagene, La Jolla, CA, USA), and verified by sequencing. The NK2 homeobox 5 (NKX2-5)-pEFSA expression plasmid and atrial natriuretic factor (ANF)-luciferase (ANF-luc) reporter, which harbors the $2,600 \mathrm{bp} 5$ '-flanking region of the $A N F$ gene and expresses Firefly luciferase, were provided by Dr Ichiro Shiojima (Chiba University School of Medicine, Chiba, Japan).

Luciferase reporter gene assays. COS-7 cells (provided by the Cardiovascular Laboratory at the Shanghai Chest Hospital) were plated in 12-well Costar culture plates (BD Biosciences,
Franklin Lakes, NJ, USA) at a density of $1 \times 10^{5}$ cells/well, and maintained in Dulbecco's modified Eagle's medium (Invitrogen; Thermo Fisher Scientific, Inc.) supplemented with $10 \%$ fetal bovine serum. Tranfections were performed on the second day of plating using Lipofectamine ${ }^{\circledR} 2000$ transfection reagent (Invitrogen; Thermo Fisher Scientific, Inc.). The pGL4.75 internal control vector, which expressed Renilla luciferase (hRluc/cytomegalovirus; Promega), was used in the transient transfection assays to normalize transfection efficiency. In each transfection experiment, the same quantity $(0.5 \mu \mathrm{g})$ of expression plasmid DNA (wild-type $T B X 5$-pcDNA3.1, NKX2-5-pEFSA or mutant $T B X 5$-pcDNA3.1) was used, either alone or in combination with $1.0 \mu \mathrm{g}$ ANF-luc and $0.04 \mu \mathrm{g}$ pGL4.75. The cells were harvested $48 \mathrm{~h}$ following transfection, and the activities of Firefly and Renilla luciferase were measured using the Dual-Glo luciferase assay system (Promega). The activity of the $A N F$ promoter was determined and expressed as the fold activation of Firefly luciferase relative to Renilla luciferase. The experiments were repeated at least three times in triplicate.

Statistical analysis. Data are expressed as the mean \pm standard deviation, unless otherwise indicated. Student's unpaired $t$-test or Fisher's exact test were used to determine significant differences. Two-tailed $\mathrm{P}<0.05$ was considered to indicate a statistically significant difference. 


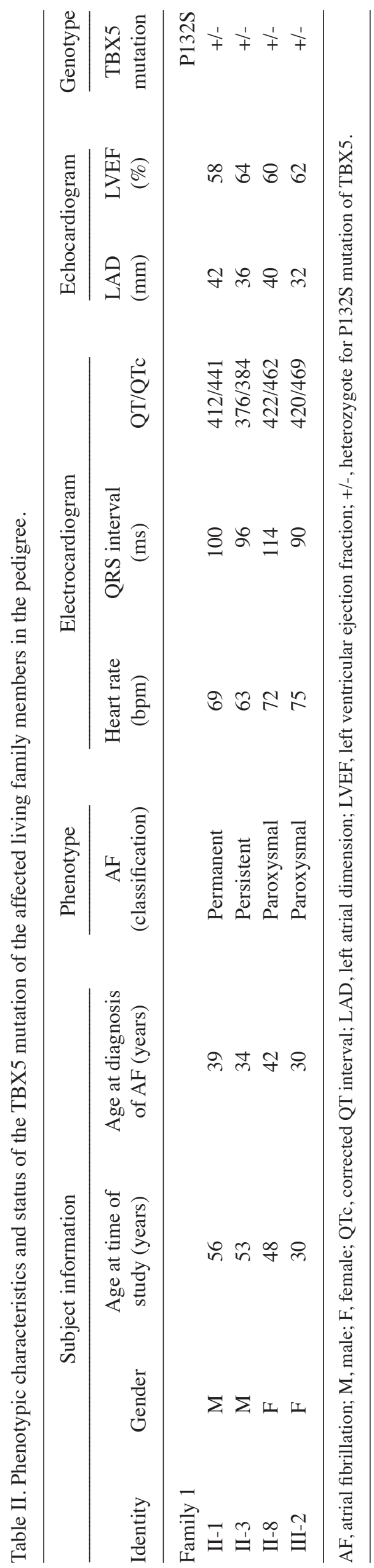

\section{Results}

Clinical characteristics of the recruited subjects. In the present study, a cohort of 190 unrelated patients with idiopathic AF was clinically evaluated and compared with 400 unrelated control individuals. All the patients had an electrocardiogram-documented AF phenotype, without known secondary causes of AF. The average age of the patients at initial diagnosis of idiopathic AF was $46 \pm 9$ years. The control individuals had normal electrocardiographic results with no history of AF occurrence. No significant differences were identified between the patient and control groups in ethnicity, gender or age. The baseline clinical characteristics of the subjects are summarized in Table I.

Identification of a novel TBX5 mutation. Through the use of sequencing, a heterozygous missense mutation in $T B X 5$ was identified in one of the 146 unrelated patients with AF, with a mutational prevalence of $\sim 0.53 \%$. Specifically, a substitution of thymine $(\mathrm{T})$ for cytosine $(\mathrm{C})$ was identified in the first nucleotide of codon 132 (c.394C $>$ T), predicting the change of proline (P) to serine (S) at amino acid position 132 (p.P132S). This mutation was in an index patient, who was diagnosed with lone AF at the age of 39 years. The DNA sequencing chromatograms, showing the heterozygous mutation of c. $394 \mathrm{C}>\mathrm{T}$ in $T B X 5$ and its control sequence, are shown in Fig. 1A. A schematic diagram of TBX5, showing the T-box structural domain and location of the mutation identified in the present study is presented in Fig. 1B. The missense mutation, which was absent in the 200 control individuals, was not found in the SNP, 1000 Genome and EVS databases (accessed on May 9, 2015). Genetic analyses of the proband's family members showed that the mutation was present in all the affected living family members, but was absent in the unaffected family members examined. Analysis of the pedigree revealed that the mutation co-segregated with $\mathrm{AF}$, and was transmitted in an autosomal dominant pattern in the family with complete penetrance. Additionally, the proband's sister (II-8) had mild bilateral forelimb deformities, a secundum atrial septal defect and atrioventricular conduction block, a phenotype of atypical Holt-Oram syndrome. The pedigree structure of the family is shown in Fig. 1C, and the phenotypic characteristics of the affected living family members are presented in Table II.

Multiple alignments of TBX5 protein sequences among various species. The alignment of multiple amino acid sequences of TBX5 proteins across species, including human, chimpanzee, monkey, dog, cattle, mouse, rat, fowl, zebrafish and frog, showed that the altered proline at amino acid residue 132 of TBX5 was completely conserved evolutionarily, suggesting that this amino acid is of functional importance (Fig. 2).

Mutant TBX5 exhibits decreased transcriptional activity As shown in Fig. 3, the same quantity $(0.5 \mu \mathrm{g})$ of the wild-type and P132S-mutant TBX5 constructs transcriptionally activated the $A N F$ promoter by $\sim 8$-fold and $\sim 4$-fold, respectively (wild-type, vs. mutant: $t=6.0007, \mathrm{P}=0.0039$ ). This indicated that the P132S-mutant TBX5 had significantly decreased 
A
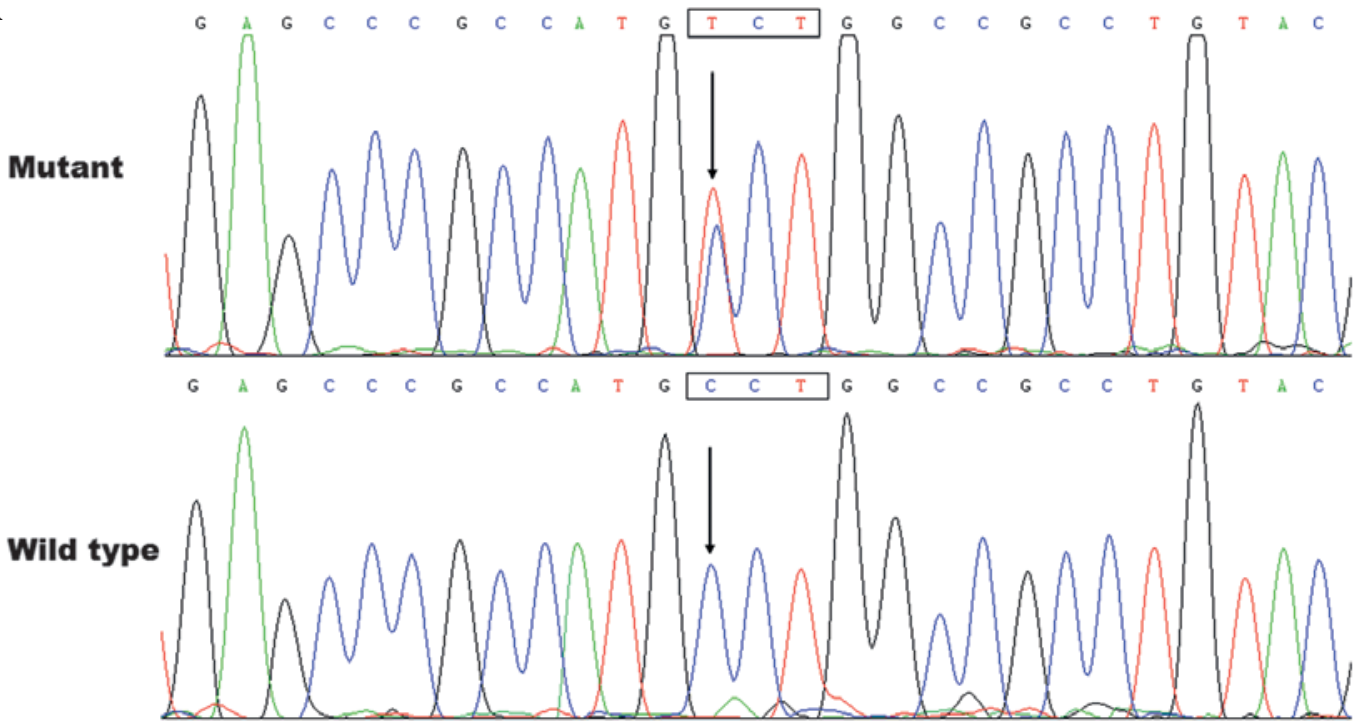

B
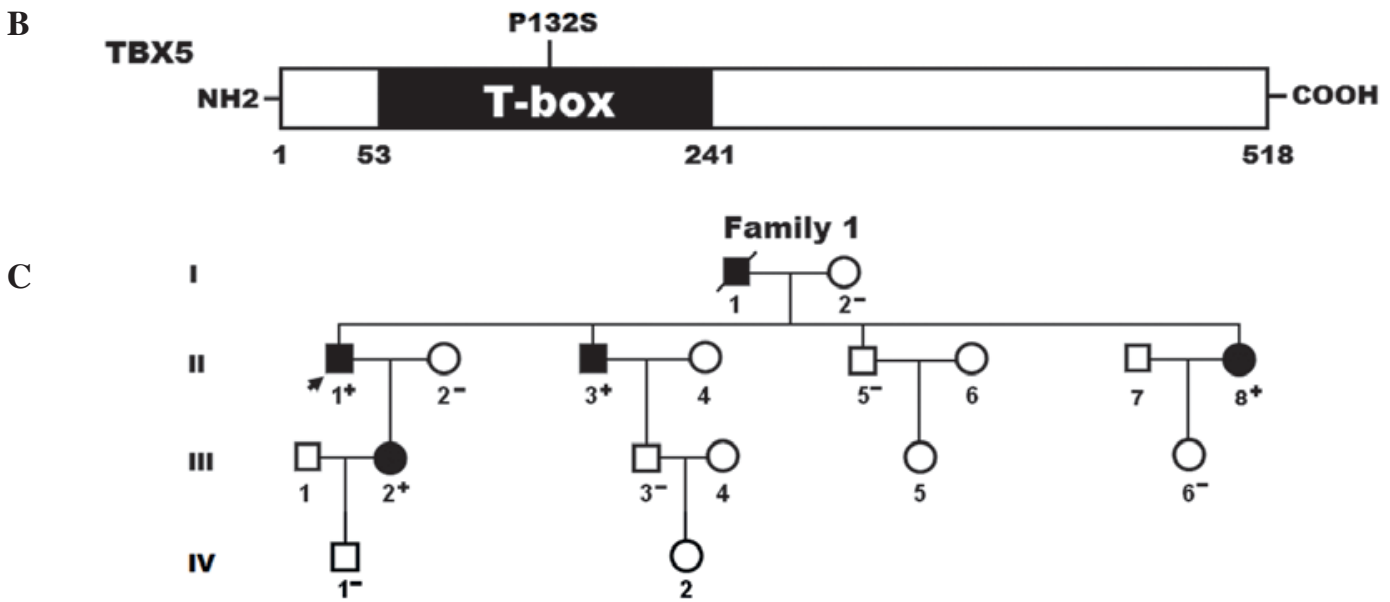

Figure 1. Novel TBX5 mutation is associated with familial AF. (A) Electropherogram output showing the heterozygous TBX5 mutation and its wild-type control The arrows point to the heterozygous nucleotides of $\mathrm{C} / \mathrm{T}$ in the proband (mutant) and the homozygous nucleotides of $\mathrm{C} / \mathrm{C}$ in the control individual (wild-type). The rectangle indicate the nucleotides, which comprise the codon of TBX5. (B) Schematic diagram of the TBX5 protein structure with the AF-associated mutation shown. The mutation identified in patients with familial AF is shown above the T-box structural domain. NH2 indicates an amino-terminus and $\mathrm{COOH}$ indicates a carboxyl-terminus. (C) Pedigree of a family containing individuals with AF-associated TBX5 mutation. The family was designated as family 1. Family members are identified by generations and numbers. Square, male family member; circle, female member; symbol with a slash, deceased member; closed symbols, affected members; open symbols, unaffected members; arrows, proband; +, carrier of TBX5 mutation; -, non-carrier. TBX, T-box; $\mathrm{AF}$, atrial fibrillation.

transcriptional activity, compared with its wild-type counterpart.

Synergistic activation is reduced between mutant TBX5 and $N K X 2-5$. As shown in Fig. 3, in the presence of $0.5 \mu \mathrm{g}$ of wild-type NKX2-5, the same quantity $(0.5 \mu \mathrm{g})$ of wild-type and P132S-mutant TBX5 induced the activation of the $A N F$ promoter by $\sim 26$-fold and $\sim 9$-fold, respectively (wild type, vs. mutant: $t=10.7419, \mathrm{P}=0.0004)$, suggesting that the mutant TBX5 had reduced synergistic transcriptional activation with NKX2-5, compared with the wild-type.

\section{Discussion}

In the present study, a novel heterozygous mutation of p.P132S in TBX5 was identified in a family comprising individuals diagnosed with AF. The missense mutation, which co-segregated with AF in the family with complete penetrance, was absent in the 800 reference chromosomes from a matched control population. The alignment of multiple TBX5 protein sequences across species revealed that the altered amino acid was completely conserved evolutionarily. Functional analysis revealed that the $\mathrm{P} 132 \mathrm{~S}$-mutant TBX5 was associated with significantly decreased transcriptional activation, which was shown when alone or in synergy with NKX2-5. Therefore, it is likely that mutated TBX5 predisposes individuals carrying this mutation to AF.

As a member of the TBX transcription factor family, $T B X 5$ is located on human chromosome $12 \mathrm{q} 24.1$, encoding a protein of 518 amino acids. The TBX5 protein contains a functionally important structural domain, termed T-box, which is essential for DNA-binding affinity and specificity, and for protein-protein interactions (27). In the present study, the TBX5 mutation identified in the patients with AF was located in the T-box, and biological analyses demonstrated that the mutation impaired the transactivational function of 


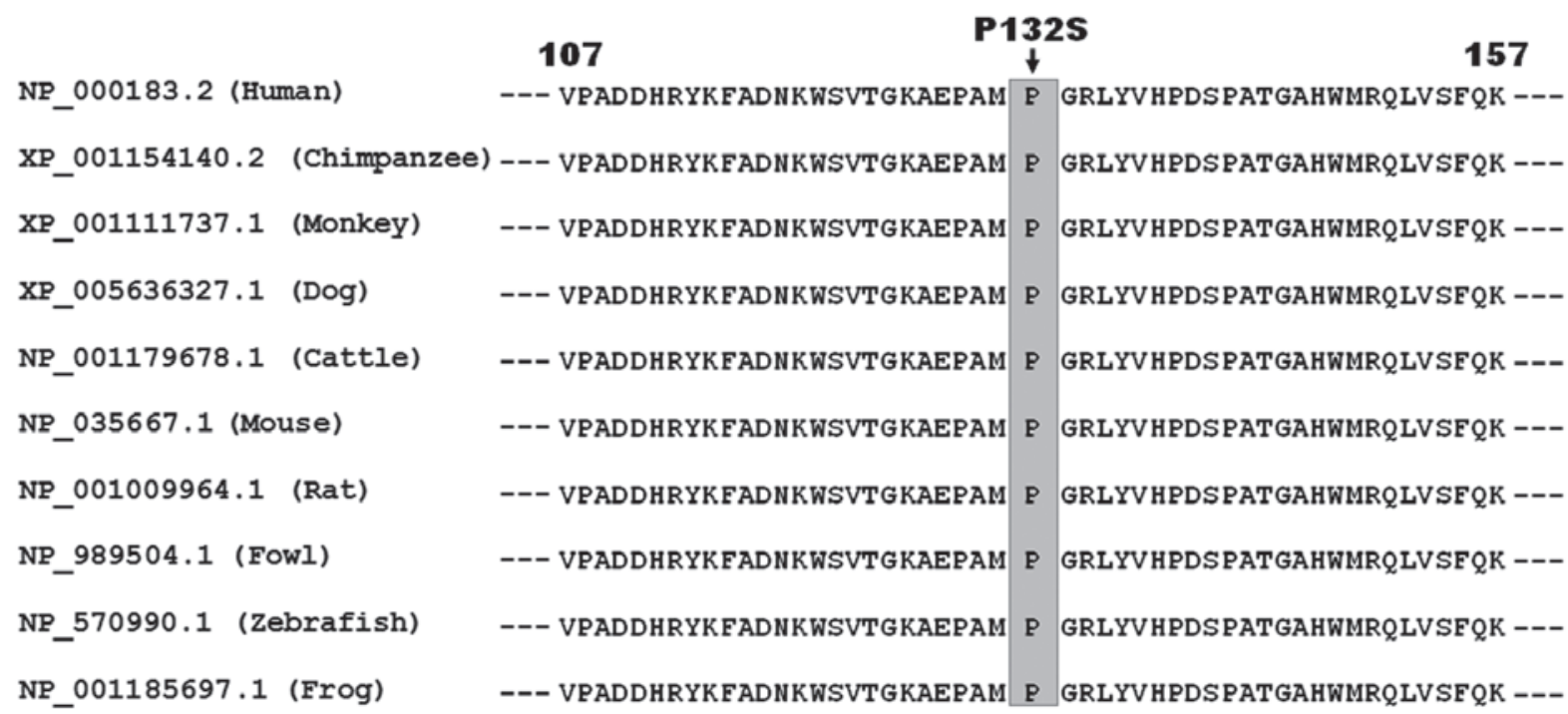

Figure 2. Multiple alignments of the TBX5 protein sequences from various species. The altered proline at amino acid position 132 of TBX5 shows complete evolutionary conservation across species. TBX, T-box.

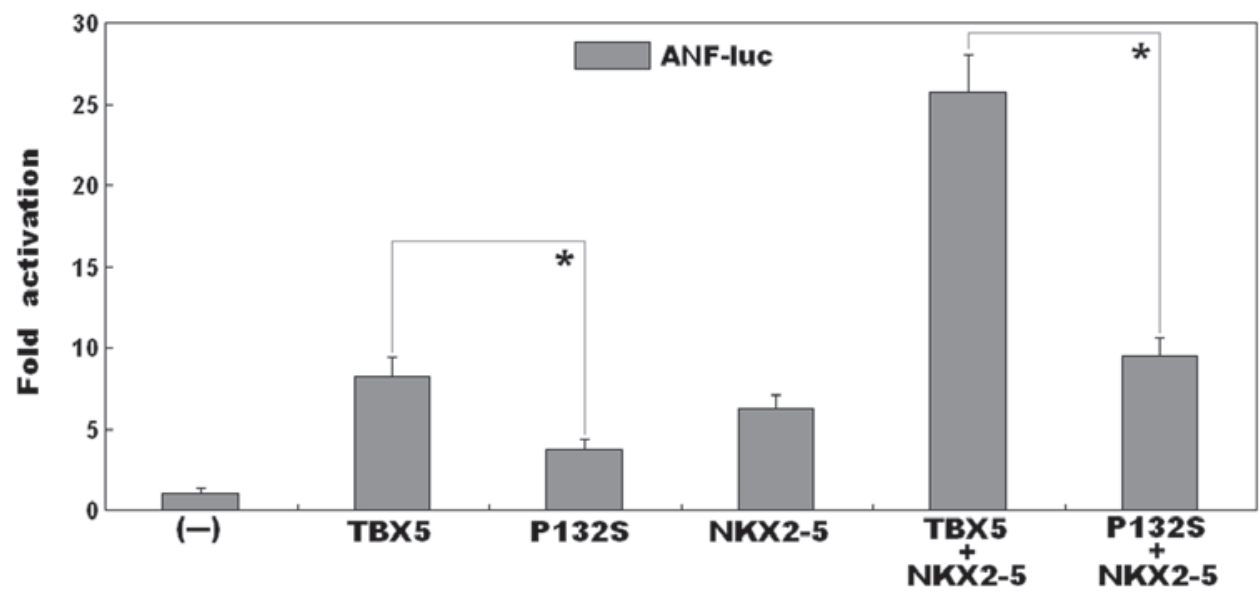

Figure 3. Effects of the TBX5 mutation on transcriptional activation in the presence and absence of NKX2-5. Transcriptional activation of ANF promoter-driven luciferase in COS-7 cells by transfection with wild-type TBX5 or P132S-mutant TBX5 (P132S), alone or together with NKX2-5. The results showed significantly decreased transcriptional activity by the mutant protein. Experiments were performed in triplicate. Results are normalized and expressed as the mean \pm standard deviation of three independent transfections. "P<0.0.5, between P132S-mutant TBX5 and wild-type TBX5. TBX, T-box; NKX2-5, NK2 homeobox 5 .

TBX5 in the absence and presence of NKX2-5. These findings suggested that haploinsufficiency or dominant-negative effects resulting from the TBX 5 mutation may be an alternative pathological mechanism of AF in a minority of patients.

The fact that the TBX5 loss-of-function mutation confers enhanced susceptibility to AF may be partially attributed to developmental defects of the heart. In humans and vertebrates, TBX5 is expressed at high levels in the embryonic heart, with a crucial role in cardiovascular development, including myocardial cell proliferation, specification, differentiation, migration, tissue patterning and morphogenesis (27). In mice, TBX5 is expressed in the cardiac crescent, linear heart tube, common atrium, ventricles, inferior and superior vena cavae, and throughout the central conduction system, including the atrioventricular node and ventricular bundle branches $(31,32)$. The homozygous deletion of TBX5 in mice leads to embryonic death, predominantly as a result of failure of cardiac looping, hypoplasia of sinuatria and left ventricle; whereas heterozygous TBX5-null mice suffer from atrial septal defects, ventricular septal defects, endocardial cushion defects, left heart hypoplasia, and distinct morphological and functional defects in the atrioventricular and bundle branch conduction systems, similar to what has been observed in patients with Holt-Oram syndrome $(32,33)$. In humans, multiple longitudinal studies have shown that abnormal cardiac conduction is an independent risk factor of AF (28,34-37). Taken together, these observational results indicate that genetically compromised TBX5 increases the susceptibility of humans to AF, most likely by causing hypoplasia of the heart, in particular within the cardiac conduction system.

Previous studies have shown that TBX5 physically interacts with other cardiac transcriptional factors, including NKX2-5, GATA4, GATA5 and GATA6, and forms a transcriptional complex to synergistically activate multiple downstream genes 
that are crucial for cardiovascular development, including $A N F$ and $C X 40$ (27,38-41). In addition, loss-of-function mutations in several transcriptionally cooperative partners and target molecules of TBX5, including NKX2-5, GATA4, GATA5, GATA6, ANF and CX40, have been implicated in the pathogenesis of AF in humans (8-14,42-44). Therefore, functionally impaired TBX5 may contribute to AF by reducing the expression of target genes.

Of note, Postma et al (28) reported that a gain-of-function mutation in TBX5 resulted in atypical Holt-Oram syndrome and AF, which was similar to prior reports showing that cytogenetic abnormalities, which produced $T B X 5$ duplication with presumed overexpression of TBX5, caused Holt-Oram syndrome-associated anomalies (45-48). In addition, several studies in experimental models have demonstrated that the biologic consequences in cells with reduced and augmented expression levels of TBX5 are similar (45,49-52). Taken together, these previous findings and those from the present study indicate that the dose of TBX5 requires fine regulation to avoid cardiovascular pathology (53).

In conclusion, to the best of our knowledge, the present study was the first to report the association of a TBX5 loss-of-function mutation with AF, which provides a novel insight into the molecular mechanisms underlying AF and has potential implications for the development of novel therapeutic strategies for AF. Furthermore the present study demonstrated that AF may be the only clinical presentation of Holt-Oram syndrome associated with a $T B X 5$ mutation, thus suggesting that there is a requirement for electrocardiographic monitoring in patients with Holt-Oram syndrome.

\section{Acknowledgements}

The present study was supported by grants from the National Natural Science Fund of China (grant nos. 81270161, 81370301, 81470372 and 81400244), the Key Program for Basic Research of Shanghai, China (grant no. 14JC1405500), the Natural Science Fund of Shanghai, China (grant nos. 13ZR1438400, 14ZR1438000 and 15ZR1438100), the Experimental animal Project of Shanghai, China (grant nos. 14140903600 and 12140902800), and the Key Project of Shanghai Chest Hospital, China (grant nos. 2014YZDH10102 and 2014YZDH20500).

\section{References}

1. January CT, Wann LS, Alpert JS, Calkins H, Cigarroa JE, Cleveland JC Jr, Conti JB, Ellinor PT, Ezekowitz MD, Field ME, et al: 2014 AHA/ACC/HRS guideline for the management of patients with atrial fibrillation: A report of the American College of Cardiology/American Heart Association Task Force on practice guidelines and the Heart Rhythm Society. Circulation 130: e199-e267, 2014.

2. Miyasaka Y, Barnes ME, Gersh BJ, Cha SS, Bailey KR, Abhayaratna WP, Seward JB and Tsang TS: Secular trends in incidence of atrial fibrillation in olmsted county, minnesota, 1980 to 2000 and implications on the projections for future prevalence. Circulation 114: 119-125, 2006.

3. Duncan ME, Pitcher A and Goldacre MJ: Atrial fibrillation as a cause of death increased steeply in England between 1995 and 2010. Europace 16: 797-802, 2014.

4. Coyne KS, Paramore C, Grandy S, Mercader M, Reynolds M and Zimetbaum P: Assessing the direct costs of treating nonvalvular atrial fibrillation in the United States. Value Health 9: 348-356, 2006.
5. Ball J, Carrington MJ, McMurray JJ and Stewart S: Atrial fibrilation: Profile and burden of an evolving epidemic in the 21st century. Int J Cardiol 167: 1807-1824, 2013.

6. Mazurek T, Kiliszek M, Kobylecka M, Skubisz-Głuchowska J, Kochman J, Filipiak K, Królicki L and Opolski G: Relation of proinflammatory activity of epicardial adipose tissue to the occurrence of atrial fibrillation. Am J Cardiol 113: 1505-1508, 2014.

7. Liu G, Yan YP, Zheng XX, Xu YL, Lu J, Hui RT and Huang XH: Meta-analysis of nonsteroidal anti-inflammatory drug use and risk of atrial fibrillation. Am J Cardiol 114: 1523-1529, 2014.

8. Hong $\mathrm{K}$ and Xiong Q: Genetic basis of atrial fibrillation. Curr Opin Cardiol 29: 220-226, 2014.

9. Wang XH, Huang CX, Wang Q, Li RG, Xu YJ, Liu X, Fang WY and Yang YQ: A novel GATA5 loss-of-function mutation underlies lone atrial fibrillation. Int J Mol Med 31: 43-50, 2013.

10. Shi HF, Yang JF, Wang Q, Li RG, Xu YJ, Qu XK, Fang WY, Liu X and Yang YQ: Prevalence and spectrum of GJA5 mutations associated with lone atrial fibrillation. Mol Med Rep 7: 767-774, 2013.

11. Sun Y, Yang YQ, Gong XQ, Wang XH, Li RG, Tan HW, Liu X, Fang WY and Bai D: Novel germline GJA5/connexin40 mutations associated with lone atrial fibrillation impair gap junctional intercellular communication. Hum Mutat 34: 603-609, 2013.

12. Huang RT, Xue S, Xu YJ, Zhou M and Yang YQ: A novel NKX2.5 loss-of-function mutation responsible for familial atrial fibrillation. Int J Mol Med 31: 1119-1126, 2013.

13. Xie WH, Chang C, Xu YJ, Li RG, Qu XK, Fang WY, Liu X and Yang YQ: Prevalence and spectrum of Nkx2.5 mutations associated with idiopathic atrial fibrillation. Clinics (Sao Paulo) 68: 777-784, 2013.

14. Yu H, Xu JH, Song HM, Zhao L, Xu WJ, Wang J, Li RG, Xu L, Jiang WF, Qiu XB, et al: Mutational spectrum of the NKX2-5 gene in patients with lone atrial fibrillation. Int J Med Sci 11: 554-563, 2014.

15. Li RG, Wang Q, Xu YJ, Zhang M, Qu XK, Liu X, Fang WY and Yang YQ: Mutations of the SCN4B-encoded sodium channel $\beta 4$ subunit in familial atrial fibrillation. Int J Mol Med 32: 144-150, 2013.

16. Beavers DL, Wang W, Ather S, Voigt N, Garbino A, Dixit SS, Landstrom AP, Li N, Wang Q, Olivotto I, et al: Mutation E169K in junctophilin-2 causes atrial fibrillation due to impaired RyR2 stabilization. J Am Coll Cardiol 62: 2010-2019, 2013.

17. Olesen MS, Refsgaard L, Holst AG, Larsen AP, Grubb S, Hauns $\varnothing$ S, Svendsen JH, Olesen SP, Schmitt N and Calloe K: A novel KCND3 gain-of-function mutation associated with early-onset of persistent lone atrial fibrillation. Cardiovasc Res 98: 488-495, 2013.

18. Yang YQ, Xu YJ,Li RG, Qu XK, Fang WY and Liu X: Prevalence and spectrum of PITX2c mutations associated with familial atrial fibrillation. Int J Cardiol 168: 2873-2876, 2013.

19. Zhou YM, Zheng PX, Yang YQ, Ge ZM and Kang WQ: A novel PITX2c loss-of-function mutation underlies lone atrial fibrillation. Int J Mol Med 32: 827-834, 2013.

20. Wang J, Zhang DF, Sun YM and Yang YQ: A novel PITX2c loss-of-function mutation associated with familial atrial fibrillation. Eur J Med Genet 57: 25-31, 2014.

21. Qiu XB, Xu YJ, Li RG, Xu L, Liu X, Fang WY, Yang YQ and Qu XK: PITX2C loss-of-function mutations responsible for idiopathic atrial fibrillation. Clinics (Sao Paulo) 69: 15-22, 2014.

22. Wang J, Zhang DF, Sun YM, Li RG, Qiu XB, Qu XK, Liu X, Fang WY and Yang YQ: NKX2-6 mutation predisposes to familial atrial fibrillation. Int J Mol Med 34: 1581-1590, 2014

23. Macri V, Mahida SN, Zhang ML, Sinner MF, Dolmatova EV, Tucker NR, McLellan M, Shea MA, Milan DJ, Lunetta KL, et al: A novel trafficking-defective HCN4 mutation is associated with early-onset atrial fibrillation. Heart Rhythm 11: 1055-1062, 2014

24. Sinner MF, Tucker NR, Lunetta KL, Ozaki K, Smith JG, Trompet S, Bis JC, Lin H, Chung MK, Nielsen JB, et al: Integrating genetic, transcriptional, and functional analyses to identify 5 novel genes for atrial fibrillation. Circulation 130: $1225-1235,2014$

25. Holm H, Gudbjartsson DF, Arnar DO, Thorleifsson G, Thorgeirsson G, Stefansdottir H, Gudjonsson SA, Jonasdottir A, Mathiesen EB, Njølstad I, et al: Several common variants modulate heart rate, $\mathrm{PR}$ interval and QRS duration. Nat Genet 42: 117-122, 2010. 
26. Zang X, Zhang S, Xia Y, Li S, Fu F, Li X, Wang F, Zhang R, Tian X, Gao L, et al: SNP rs3825214 in TBX5 is associated with lone atrial fibrillation in Chinese Han population. PLoS One 8: e64966, 2013.

27. Greulich F, Rudat $C$ and Kispert A: Mechanisms of T-box gene function in the developing heart. Cardiovasc Res 91: 212-222, 2011.

28. Postma AV, van de Meerakker JB, Mathijssen IB, Barnett P, Christoffels VM, Ilgun A, Lam J, Wilde AA, Lekanne Deprez RH and Moorman AF: A gain-of-function TBX5 mutation is associated with atypical Holt-Oram syndrome and paroxysmal atrial fibrillation. Circ Res 102: 1433-1442, 2008.

29. World Medical Association: World Medical Association Declaration of Helsinki: Ethical principles for medical research involving human subjects. J Postgrad Med 48: 206-208, 2002.

30. Zhang XL, Qiu XB, Yuan F, Wang J, Zhao CM, Li RG, Xu L, Xu YJ, Shi HY, Hou XM, et al: TBX5 loss-of-function mutation contributes to familial dilated cardiomyopathy. Biochem Biophys Res Commun 459: 166-171, 2015.

31. Bruneau BG, Logan M, Davis N, Levi T, Tabin CJ, Seidman JG and Seidman CE: Chamber-specific cardiac expression of Tbx5 and heart defects in Holt-Oram syndrome. Dev Biol 211: 100-108, 1999.

32. Moskowitz IP, Pizard A, Patel VV, Bruneau BG, Kim JB, Kupershmidt S, Roden D, Berul CI, Seidman CE and Seidman JG: The T-Box transcription factor Tbx 5 is required for the patterning and maturation of the murine cardiac conduction system. Development 131: 4107-4116, 2004.

33. Bruneau BG, Nemer G, Schmitt JP, Charron F, Robitaille L, Caron S, Conner DA, Gessler M, Nemer M, Seidman CE and Seidman JG: A murine model of Holt-Oram syndrome defines roles of the T-box transcription factor Tbx 5 in cardiogenesis and disease. Cell 106: 709-721, 2001.

34. Cheng S, Keyes MJ, Larson MG, McCabe EL, Newton-Cheh C, Levy D, Benjamin EJ, Vasan RS and Wang TJ: Long-term outcomes in individuals with prolonged PR interval or first-degree atrioventricular block. JAMA 301: 2571-2577, 2009.

35. Soliman EZ, Prineas RJ, Case LD, Zhang ZM and Goff DC Jr.: Ethnic distribution of ECG predictors of atrial fibrillation and its impact on understanding the ethnic distribution of ischemic stroke in the Atherosclerosis Risk in Communities (ARIC) study. Stroke 40: 1204-1211, 2009.

36. Schnabel RB, Sullivan LM, Levy D, Pencina MJ, Massaro JM, D'Agostino RB Sr, Newton-Cheh C, Yamamoto JF, Magnani JW, Tadros TM, et al: Development of a risk score for atrial fibrillation (Framingham Heart Study): A community-based cohort study. Lancet 373: 739-745, 2009.

37. Macfarlane PW, Murray H, Sattar N, Stott DJ, Ford I, Buckley B, Jukema JW, Westendorp RG and Shepherd J: The incidence and risk factors for new onset atrial fibrillation in the PROSPER study. Europace 13: 634-639, 2011.

38. Hiroi Y, Kudoh S, Monzen K, Ikeda Y, Yazaki Y, Nagai R and Komuro I: Tbx 5 associates with $\mathrm{Nkx} 2-5$ and synergistically promotes cardiomyocyte differentiation. Nat Genet 28: 276-280, 2001.
39. Garg V, Kathiriya IS, Barnes R, Schluterman MK, King IN, Butler CA, Rothrock CR, Eapen RS, Hirayama-Yamada K, Joo K, et al: GATA4 mutations cause human congenital heart defects and reveal an interaction with TBX5. Nature 424: 443-447, 2003

40. Linhares VL, Almeida NA, Menezes DC, Elliott DA, Lai D, Beyer EC, Campos de Carvalho AC and Costa MW: Transcriptional regulation of the murine Connexin40 promoter by cardiac factors $\mathrm{Nkx} 2-5$, GATA4 and Tbx5. Cardiovasc Res 64: 402-411, 2004.

41. Maitra M, Schluterman MK, Nichols HA, Richardson JA, Lo CW, Srivastava D and Garg V: Interaction of Gata4 and Gata6 with Tbx 5 is critical for normal cardiac development. Dev Biol 326: 368-377, 2009

42. Jiang JQ, Shen FF, Fang WY, Liu X and Yang YQ: Novel GATA4 mutations in lone atrial fibrillation. Int J Mol Med 28: 1025-1032, 2011.

43. Li J, Liu WD, Yang ZL and Yang YQ: Novel GATA6 loss-of-function mutation responsible for familial atrial fibrillation. Int J Mol Med 30: 783-790, 2012.

44. Hodgson-Zingman DM, Karst ML, Zingman LV, Heublein DM, Darbar D, Herron KJ, Ballew JD, de Andrade M, Burnett JC Jr and Olson TM: Atrial natriuretic peptide frameshift mutation in familial atrial fibrillation. N Engl J Med 359: 158-165, 2008.

45. McDermott DA, Hatcher CJ and Basson CT: Atrial fibrillation and other clinical manifestations of altered TBX5 dosage in typical Holt-Oram syndrome. Circ Res 103: e96, 2008.

46. Patel C, Silcock L, McMullan D, Brueton L and Cox H: TBX5 intragenic duplication: A family with an atypical Holt-Oram syndrome phenotype. Eur J Hum Genet 20: 863-869, 2012.

47. Kimura M, Kikuchi A, Ichinoi N and Kure S: Novel TBX5 duplication in a Japanese family with Holt-Oram syndrome. Pediatr Cardiol 36: 244-247, 2015.

48. Al-Qattan MM and Abou Al-Shaar H: Molecular basis of the clinical features of Holt-Oram syndrome resulting from missense and extended protein mutations of the TBX5 gene as well as TBX5 intragenic duplications. Gene 560: 129-136, 2015.

49. Hatcher CJ, Kim MS, Mah CS, Goldstein MM, Wong B, Mikawa T and Basson CT: TBX5 transcription factor regulates cell proliferation during cardiogenesis. Dev Biol 230: 177-188, 2001.

50. Hatcher CJ, Diman NY, Kim MS, Pennisi D, Song Y, Goldstein MM, Mikawa T and Basson CT: A role for Tbx 5 in proepicardial cell migration during cardiogenesis. Physiol Genomics 18: 129-140, 2004.

51. Liberatore CM, Searcy-Schrick RD and Yutzey KE: Ventricular expression of tbx 5 inhibits normal heart chamber development. Dev Biol 223: 169-180, 2000

52. Al-Qattan MM and Abou Al-Shaar H: Molecular basis of the clinical features of Holt-Oram syndrome resulting from missense and extended protein mutations of the TBX5 gene as well as TBX5 intragenic duplications. Gene 560: 129-136, 2015.

53. Mori AD, Zhu Y, Vahora I, Nieman B, Koshiba-Takeuchi K, Davidson L, Pizard A, Seidman JG, Seidman CE, Chen XJ, et al: Tbx5-dependent rheostatic control of cardiac gene expression and morphogenesis. Dev Biol 297: 566-586, 2006. 